\title{
SCIENTIFIC REPORTS

\section{OPEN Investigation of a tellurium-packed column for isolation of astatine-211 from irradiated bismuth targets and demonstration of a semi- automated system}

\author{
Yawen Li $\mathbb{1}^{*}$, Donald K. Hamlin, Ming-Kuan Chyan, Taylor M. Morscheck, Maryline G. Ferrier, \\ Roger Wong \& D. Scott Wilbur
}

Astatine-211 is an attractive radionuclide for use in targeted alpha therapy of blood-borne diseases and micrometastatic diseases. Efficient isolation methods that can be adapted to robust automated ${ }^{211} \mathrm{At}$ isolation systems are of high interest for improving the availability of ${ }^{211} \mathrm{At}$. Based on the early studies of Bochvarova and co-workers involving isolation of ${ }^{211} \mathrm{At}$ from irradiated thorium targets, we developed a method for ${ }^{211} \mathrm{At}$ isolation from bismuth targets using tellurium-packed columns. Dissolution of irradiated bismuth targets is accomplished using $\mathrm{HNO}_{3}$ i however, ${ }^{211} \mathrm{At}$ is not captured on the Te column material in this matrix. Our method involves slow addition of aqueous $\mathrm{NH}_{2} \mathrm{OH} \cdot \mathrm{HCl}$ to the $\mathrm{Bi}$ target dissolved in $\mathrm{HNO}_{3}$ to convert to a $\mathrm{HCl}$ matrix. The amount of $\mathrm{NH}_{2} \mathrm{OH} \cdot \mathrm{HCl}$ was optimized because (1) the quantity of $\mathrm{NH}_{2} \mathrm{OH} \cdot \mathrm{HCl}$ used appears to affect the radiolabeling yield of phenethyl-closo-decaborate(2-) (B10)-conjugated antibodies and (2) reducing the volume of $\mathrm{NH}_{2} \mathrm{OH} \cdot \mathrm{HCl}$ solution can effectively shorten the overall isolation time. A proof-of-concept semi-automated process has been demonstrated using targets containing $\sim 0.96 \mathrm{GBq}(\sim 26 \mathrm{mCi})$ of ${ }^{211} \mathrm{At}$. High isolation yields $(88-95 \%)$ were obtained. Radiochemical purity of the isolated ${ }^{211} \mathrm{At}$ was assessed by radio-HPLC. Concentrations of $\mathrm{Bi}$ and Te contaminants in the ${ }^{211} \mathrm{At}$ and the astatinated antibodies were evaluated using ICP-MS.

Astatine-211 is one of the most attractive radionuclides for targeted alpha therapy (TAT) ${ }^{1-4}$. It has a $7.21 \mathrm{~h}$ half-life, very low abundance of high energy gamma-ray emissions and $100 \%$ alpha emission. Astatine- $211 \mathrm{can}$ be produced by bombardment of high purity bismuth metal (naturally monoisotopic) targets with $28-29 \mathrm{MeV}$ alpha particles. Dry distillation is widely used for isolation of ${ }^{211}$ At from irradiated Bi targets. Various dry distillation set-ups have been described in the literature ${ }^{5-11}$, but handling of radioactive gases has raised concerns by institutional radiation safety officials. Moreover, if large quantities of ${ }^{211}$ At are to be produced, the size of bismuth target must be increased significantly. This increase in size of target is due to the low melting point of $\mathrm{Bi}$ $\left(271.5^{\circ} \mathrm{C}\right)$, requiring that the alpha beam be spread over a large area to provide efficient cooling during irradiation. Implementing the dry distillation method when using larger bismuth targets can present significant challenges due to the fact that increasing the size of the quartz tube for distillation of Bi can make it difficult to find commercial tube ovens for this purpose and the larger tubes can make the distillation process less efficient ${ }^{12}$. An alternative to placing large irradiated bismuth targets (and their backing material) in an oven is to mechanically remove the irradiated bismuth from the target backing, followed by placing the bismuth in a high temperature oven $\left(650-750^{\circ} \mathrm{C}\right)^{5}$. The safety of this process has also raised concerns from radiation safety officials.

An alternative method of isolating ${ }^{211}$ At from irradiated bismuth targets involves "wet chemistry" liquid-liquid extraction processes ${ }^{13-17}$. We have been able to consistently obtain high isolation yields using this method, but it is a 2.5-3 hour process where distillation of concentration $\mathrm{HNO}_{3}$ and multiple liquid-liquid extraction steps are required ${ }^{12}$. In the isolation process irradiated bismuth targets are dissolved in concentrated $\mathrm{HNO}_{3}$, but the organic phase used, diisopropyl ether (DIPE), cannot effectively extract ${ }^{211} \mathrm{At}$ from $\mathrm{HNO}_{3}$ solutions. Therefore, the $\mathrm{HNO}_{3}$ 


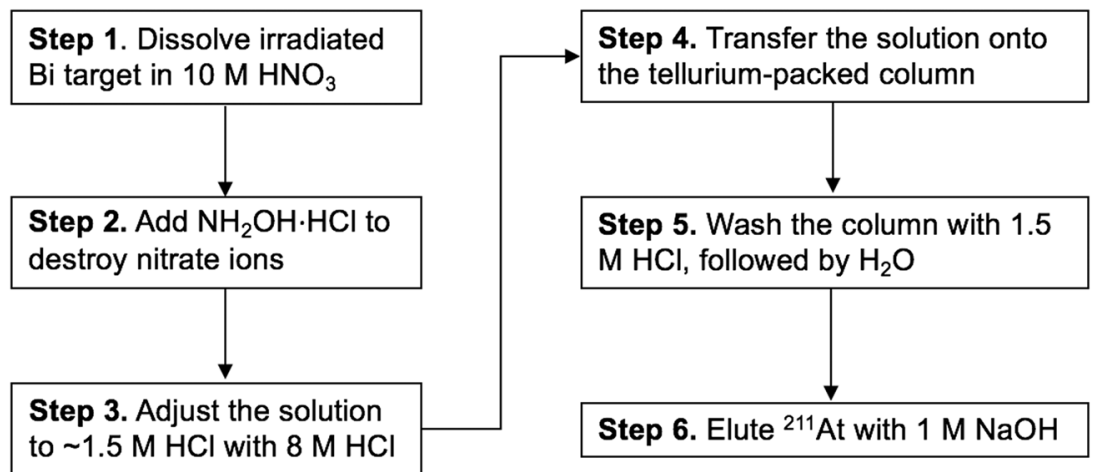

Figure 1. Flow chart for the isolation process of ${ }^{211}$ At from irradiated Bi targets using Te columns.

\begin{tabular}{|l|l|l|l|l|}
\hline $\begin{array}{l}\text { Loading } \\
\text { solution }\end{array}$ & $\begin{array}{l}\text { \% Captured by } \\
\text { Te column }\end{array}$ & $\begin{array}{l}\text { \% Activity in } \\
\text { HCl wash } \\
(\mathbf{2 0} \mathbf{~ m L})\end{array}$ & $\begin{array}{l}\text { \% Activity in } \\
\begin{array}{l}\mathbf{H}_{\mathbf{2}} \mathbf{O} \text { wash } \\
\mathbf{2 0} \mathbf{~ m L})\end{array}\end{array}$ & $\begin{array}{l}\text { \%11 At eluted in 1st } \\
\mathbf{1} \mathbf{~} \mathbf{~ N a O H} \\
\text { (decay-corrected) }\end{array}$ \\
\hline $1.5 \mathrm{M} \mathrm{HCl}$ & $>99.9$ & $<0.1$ & $<0.1$ & $78.9-87.7$ \\
\hline $\begin{array}{l}0.1 \mathrm{M} \mathrm{SnCl} \\
\text { in } 6 \mathrm{M} \mathrm{HCl}\end{array}$ & 99.5 & $<0.1^{b}$ & $<0.1$ & 75 \\
\hline
\end{tabular}

Table 1. Isolation yields of ${ }^{211} \mathrm{At}$ using Te columns in the presence or absence of $\mathrm{SnCl}_{2}$ in the loading mixture ${ }^{a}$. ${ }^{a} 35 \%$ aqueous $\mathrm{NH}_{2} \mathrm{OH} \cdot \mathrm{HCl}$ was added until the cessation of bubbling. ${ }^{b}$ The Te column was eluted with $20 \mathrm{~mL}$ of $0.1 \mathrm{M} \mathrm{SnCl}_{2}$ in $6 \mathrm{M} \mathrm{HCl}$, followed by $20 \mathrm{~mL}$ of $6 \mathrm{M} \mathrm{HCl}$.

is removed by distillation and $8 \mathrm{M} \mathrm{HCl}$ is used to re-dissolve the $\mathrm{Bi}\left(\mathrm{NO}_{3}\right)_{3}$ salt residue. Liquid-liquid extractions are then performed to isolate ${ }^{211} \mathrm{At}$ from the ${ }^{211} \mathrm{At} / \mathrm{Bi}^{3+}$ mixture and to remove $\mathrm{Bi}^{3+}$ salts using DIPE and $8 \mathrm{M} \mathrm{HCl}$. We have investigated automation of this wet chemistry, liquid-liquid exaction method for ${ }^{211}$ At isolation, and although it has been technically challenging, we have had some success in automation ${ }^{18}$. Unfortunately, thus far we have not been able to decrease the time required using the automated "wet chemistry" ${ }^{111}$ At isolation process from that achieved in the manual separation procedure (unpublished data). In an effort to simplify the isolation process and decrease the time to obtain the isolated ${ }^{211} \mathrm{At}$, we looked for alternative isolation methods.

During the separation process in the wet chemistry method, astatine undergoes several changes in its oxidation state, possibly from $\operatorname{At}(+5)$ to $\operatorname{At}(+3)$, then to $\operatorname{At}(0)$, and finally to $\operatorname{At}(-1)^{14}$. Along with the change in oxidation state there are likely different chemical species produced. In addition to astatide, four other unknown astatine species have been observed at different times by anion exchange radio-HPLC ${ }^{12}$. The inconsistency in the radiochemical purity of the ${ }^{211} \mathrm{At}$ isolated using the DIPE extraction method can result in poor radiolabeling yields, which can be a major problem in fulfilling prescribed doses in the clinical setting.

Here we report a new ${ }^{211}$ At-isolation approach based on a tellurium-packed column (Te column) previously described in the literature. Bochvarova et al. reported a method of using two tellurium metal packed columns to effectively isolate ${ }^{211} \mathrm{At}$ from $660 \mathrm{MeV}$ proton beam irradiated thorium targets ${ }^{19}$. Astatine- 211 can be rapidly absorbed on metallic tellurium in $\mathrm{HCl}$ in the presence of $\mathrm{SnCl}_{2}$ and eluted by a solution of $1-2 \mathrm{M} \mathrm{NaOH}$. In order to adapt the Te column method to irradiated bismuth targets, we used $\mathrm{NH}_{2} \mathrm{OH} \cdot \mathrm{HCl}$ to convert the $\mathrm{HNO}_{3}$ solution containing the dissolved target to a solution of $\mathrm{HCl}$. We also demonstrated this new method can be readily automated and can provide $\left[{ }^{211} \mathrm{At}\right] \mathrm{NaAt}$ of consistent and high radiochemical purity.

\section{Results}

At-211 isolation using Te columns. Figure 1 summarizes the steps involved in the process of isolating ${ }^{211}$ At from irradiated Bi targets using Te columns. Step 1 involves dissolution of the bismuth target using $10 \mathrm{M}$ $\mathrm{HNO}_{3}$. This is the same initial step used in the automation of the wet chemistry isolation process ${ }^{18}$. Step 2 involves addition of $\mathrm{NH}_{2} \mathrm{OH} \cdot \mathrm{HCl}$ to the $\mathrm{HNO}_{3}$ solution containing dissolved Bi dropwise until complete cessation of bubbling is noted. Steps 3-6 are conducted as shown in Fig. 1. However, in our initial studies steps 3 and 5 were slightly different, as a reductant, $\mathrm{SnCl}_{2}$ was used to assure that the ${ }^{211} \mathrm{At}$ was in the astatide form. The steps initially used were as follows: In step 3, $0.1 \mathrm{M} \mathrm{SnCl}_{2}$ in $6 \mathrm{M} \mathrm{HCl}$ was used instead of $1.5 \mathrm{M} \mathrm{HCl}$ and in step 5 , the column was washed by $0.1 \mathrm{M} \mathrm{SnCl}_{2}$ in $6 \mathrm{M} \mathrm{HCl}, 6 \mathrm{M} \mathrm{HCl}$ and deionized (D.I.) $\mathrm{H}_{2} \mathrm{O}$ sequentially. As $\mathrm{NH}_{2} \mathrm{OH} \cdot \mathrm{HCl}$ is a strong reducing agent, the use of $0.1 \mathrm{M} \mathrm{SnCl}_{2}$ seemed to be redundant but we thought it would be best to evaluate isolation yields with and without having $\mathrm{SnCl}_{2}$ present.

Table 1 shows that the astatine adsorption kinetics of the Te column is very fast and efficient, irrespective of whether $\mathrm{SnCl}_{2}$ was used or not. Essentially all of the ${ }^{211} \mathrm{At}$ was absorbed by the Te column from $1.5 \mathrm{M} \mathrm{HCl}$ even at a high flow rate of $5-10 \mathrm{~mL} / \mathrm{min}$. Moreover, very little activity was found in the washes $(<0.1 \%)$ and isolation yields $\sim 75 \%$ were obtained when the ${ }^{211} \mathrm{At} / \mathrm{Bi}$ mixture was adjusted to $0.1 \mathrm{M} \mathrm{SnCl}_{2}$ in $6 \mathrm{M} \mathrm{HCl}$. Comparable or even higher ${ }^{211} \mathrm{At}$ isolation yields were obtained without the use of $\mathrm{SnCl}_{2}$ (Table 1). Therefore, the later ${ }^{211} \mathrm{At}$ isolation experiments were conducted without $\mathrm{SnCl}_{2}$, as outlined in Fig. 1. 


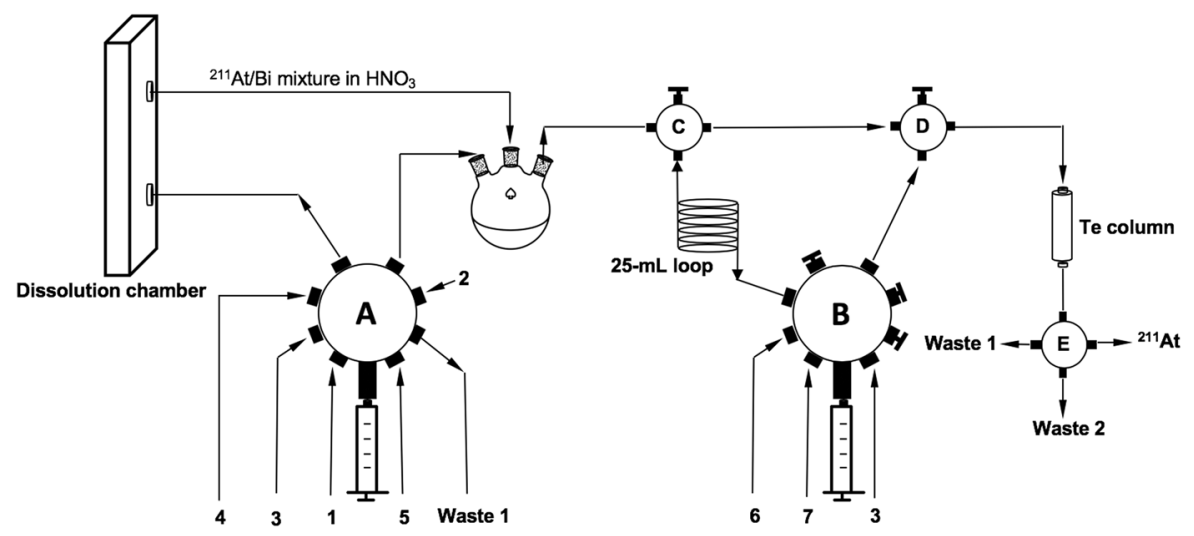

Figure 2. Schematic of the semi-automated process of ${ }^{211}$ At isolation using a Te column. In the process two syringe pumps move the solvents and mixtures through valves (A-E). Numbered solutions are as follows: 1: $10 \mathrm{M} \mathrm{HNO}_{3}$; 2: air; 3: D.I. $\mathrm{H}_{2} \mathrm{O}$; 4: 35\% $\mathrm{NH}_{2} \mathrm{OH} \cdot \mathrm{HCl}$; 5: $8 \mathrm{M} \mathrm{HCl}$; : $1.5 \mathrm{M} \mathrm{HCl}$; $1 \mathrm{M} \mathrm{NaOH}$. Waste 1: nonradioactive waste; Waste 2: radioactive waste. (Detailed description of equipment and reagents can be found in Fig. S1).

\begin{tabular}{|l|l|l|l|l|l|}
\hline & $\begin{array}{l}\mathbf{N H}_{2} \mathrm{OH} \cdot \mathrm{HCl} \\
(\mathbf{m L})\end{array}$ & $\begin{array}{l}\mathbf{1 . 5} \mathrm{M} \text { HCl wash } \\
(\mathbf{m L})\end{array}$ & $\begin{array}{l}\mathrm{H}_{2} \mathrm{O} \text { wash } \\
(\mathbf{m L})\end{array}$ & $\begin{array}{l}\text { \% Isolation yield } \\
(\text { decay-corrected) }\end{array}$ & $\begin{array}{l}\text { Run time } \\
(\mathbf{m i n})\end{array}$ \\
\hline 1 & 80 & 20 & 20 & 95.3 & 100 \\
\hline 2 & 80 & 20 & 20 & $88^{a}$ & 100 \\
\hline 3 & 65 & 40 & 40 & 96.7 & 90 \\
\hline
\end{tabular}

Table 2. Quantities of reagents, isolated yields and run times from three semi-automated ${ }^{211}$ At isolation experiments. ${ }^{a}$ Lost $5-10 \%$ of the activity because a ferrule fitting of the dissolution chamber leaked during the run.

Semi-automated ${ }^{211}$ At isolation runs. The results of the manual ${ }^{211}$ At isolation runs were very encouraging, so the procedure was adapted to a semi-automated system to demonstrate potential application of the Te column method for routine ${ }^{211}$ At isolation. Three proof-of-concept semi-automated ${ }^{211}$ At isolation runs were conducted using irradiated bismuth targets following the procedure outlined in Fig. 1. The schematic of the semi-automated process is shown in Fig. 2. A picture of our prototype is shown in Fig. S1. Results of the semi-automated runs are summarized in Table 2. The irradiated bismuth targets each contained about $962 \mathrm{MBq}$ $(26 \mathrm{mCi})$ and the overall ${ }^{211} \mathrm{At}$ isolation process run time was $90-100$ minutes. On average, the system was able to recover $93 \pm 4 \%$ of the ${ }^{211} \mathrm{At}$ in $2 \mathrm{~mL}$ of $1 \mathrm{M} \mathrm{NaOH}$. For the $1^{\text {st }}$ and $2^{\text {nd }}$ semi-automated runs, $80 \mathrm{~mL}$ of $35 \%$ aqueous $\mathrm{NH}_{2} \mathrm{OH} \cdot \mathrm{HCl}$ was used and the columns were washed with $20 \mathrm{~mL}$ of $1.5 \mathrm{M} \mathrm{HCl}$, followed by $20 \mathrm{~mL}$ of deionized (D.I.) $\mathrm{H}_{2} \mathrm{O}$. For the $3^{\text {rd }}$ semi-automated run, the volume of $35 \% \mathrm{NH}_{2} \mathrm{OH} \cdot \mathrm{HCl}$ was reduced by $15 \mathrm{~mL}$ which appears to be enough to destroy all of the nitrate. Decreasing the volume of aqueous $\mathrm{NH}_{2} \mathrm{OH} \cdot \mathrm{HCl}$ reduced the overall run time, even though an additional $20 \mathrm{~mL}$ of $1.5 \mathrm{M} \mathrm{HCl}$ and D.I. $\mathrm{H}_{2} \mathrm{O}$ was used for washing the column in the $3^{\text {rd }}$ semi-automated run.

Optimization of the amount of $\mathrm{NH}_{2} \mathrm{OH} \cdot \mathrm{HCl}$. Although the ${ }^{211}$ At isolation yields were encouraging when an excess of $\mathrm{NH}_{2} \mathrm{OH} \cdot \mathrm{HCl}$ was used, we obtained inconsistent radiolabeling yields, ranging from $10.4 \%$ to $94.7 \%$, when using the isolated ${ }^{211}$ At solutions to label isothiocyanato-phenethyl-closo-decaborate (2-) (B10-NCS)-conjugated monoclonal antibodies (MAbs) at room temperature in the absence of an oxidant. We also observed that addition of the oxidant chloramine-T improved the MAb-B10 radiolabeling yield, suggesting that there might be reductive impurities in the isolated ${ }^{211}$ At solution.

We hypothesized optimizing the amount of $\mathrm{NH}_{2} \mathrm{OH} \cdot \mathrm{HCl}$ might mitigate this problem. Experiments were conducted to determine the minimal volume of $35 \% \mathrm{NH}_{2} \mathrm{OH} \cdot \mathrm{HCl}$ required to destroy all the $\mathrm{NO}_{3}{ }^{-}\left(\mathrm{V}_{\min }\right)$ in the $\mathrm{HNO}_{3}$ solution containing the dissolved $\mathrm{Bi}$ target, as it seemed to be impossible to accurately assign defined stoichiometry to the reaction between $\mathrm{NH}_{2} \mathrm{OH} \cdot \mathrm{HCl}$ and $\mathrm{HNO}_{3}$. Minimally, about $52 \mathrm{~mL}$ of $35 \% \mathrm{NH}_{2} \mathrm{OH} \cdot \mathrm{HCl}$ is needed for a Bi target that is dissolved in $15 \mathrm{~mL}$ of $10 \mathrm{M} \mathrm{HNO}_{3}$. A series of manual ${ }^{211} \mathrm{At}$ isolations were conducted using different percentages of $\mathrm{V}_{\min }$. Table 3 shows that although the ${ }^{211} \mathrm{At}$ isolation yield decreased as the volume of $35 \% \mathrm{NH}_{2} \mathrm{OH} \cdot \mathrm{HCl}$ was reduced, the radiolabeling yields for B10-conjugated $\mathrm{MAb}$ increased significantly. Reducing the amount of $\mathrm{NH}_{2} \mathrm{OH} \cdot \mathrm{HCl}$ to $52 \%$ of $\mathrm{V}_{\min }$ appears to be optimal, as the radiolabeling yield increased to $82.5 \%$, equivalent to the normal radiolabeling yield achieved with ${ }^{211}$ At isolated using the DIPE method. And at $52 \%$ of $\mathrm{V}_{\min }$, an isolation yield of about $80 \%$ could still be obtained.

Chemical and radiochemical purity. The Te column method can effectively isolate ${ }^{211}$ At from large-sized Bi targets containing 4-5 g of Bi metal, but trace levels of Te and Bi impurities in the isolated ${ }^{211}$ At solutions were anticipated. The concentrations of Te and Bi impurities in the ${ }^{211} \mathrm{At}$ solutions were evaluated by ICP-MS after the 


\begin{tabular}{|c|c|c|c|c|c|}
\hline $\begin{array}{l}\mathrm{NH}_{2} \mathrm{OH} \cdot \mathrm{HCl} \\
\left(\% \mathrm{~V}_{\min }\right)\end{array}$ & $\begin{array}{l}\text { \% Captured by } \\
\text { Te column }\end{array}$ & $\begin{array}{l}\% \text { Activity in } \\
\mathrm{HCl} \text { wash }(20 \mathrm{~mL})\end{array}$ & $\begin{array}{l}\text { \% Activity in } \\
\mathrm{H}_{2} \mathrm{O} \text { wash } \\
(20 \mathrm{~mL})\end{array}$ & $\begin{array}{l}\%^{211} \text { At eluted in the } 1 \text { st } \\
1 \mathrm{~mL} \mathrm{NaOH} \\
\text { (decay-corrected) }\end{array}$ & $\begin{array}{l}\text { \% B10-conjugated } \\
\text { MAb labeling yield }\end{array}$ \\
\hline$\geq 100$ & $>99.9$ & $<0.1$ & $<0.1$ & $78.9-87.7$ & $10.4-94.7$ \\
\hline 95 & $>99.9$ & $<0.1$ & $<0.1$ & 86.6 & 17.0 \\
\hline 83 & $>99.9$ & $<0.1$ & $<0.1$ & 83.7 & 26.0 \\
\hline 80 & 98.7 & $<0.1$ & $<0.1$ & \begin{tabular}{|l|}
80.5 \\
\end{tabular} & 23.4 \\
\hline 68 & $>99.9$ & 0.13 & $<0.1$ & 78.1 & 29.8 \\
\hline 52 & 99.5 & 0.20 & $<0.1$ & 79.8 & 82.5 \\
\hline 46 & 98.9 & 0.30 & $<0.1$ & 70.2 & 72.9 \\
\hline
\end{tabular}

Table 3. Using various amounts of $\mathrm{NH}_{2} \mathrm{OH} \cdot \mathrm{HCl}$ for ${ }^{211} \mathrm{At}$ isolation and its influence on the $\mathrm{B} 10$-conjugated MAb labeling yield.

\begin{tabular}{|l|l|l|l|}
\hline & Te (ppm) & Bi (ppm) \\
\cline { 2 - 4 } & Te column & Te column & DIPE \\
\hline $\begin{array}{l}\left.{ }^{211} \mathrm{At}\right] \mathrm{NaAt} \\
(\mathrm{n}=10)\end{array}$ & $32.8 \pm 15.8$ & $3.0 \pm 2.5$ & $1.7 \pm 1.5$ \\
\hline $\begin{array}{l}\text { 211 At labeled } \\
\text { MAb }(\mathrm{n}=3)\end{array}$ & $0.04 \pm 0.01$ & $0.05 \pm 0.04$ & n.a. \\
\hline
\end{tabular}

Table 4. Levels of Te and Bi impurities in isolated ${ }^{211} \mathrm{At}$ and ${ }^{211} \mathrm{At}-\mathrm{labeled} \mathrm{MAb}$.

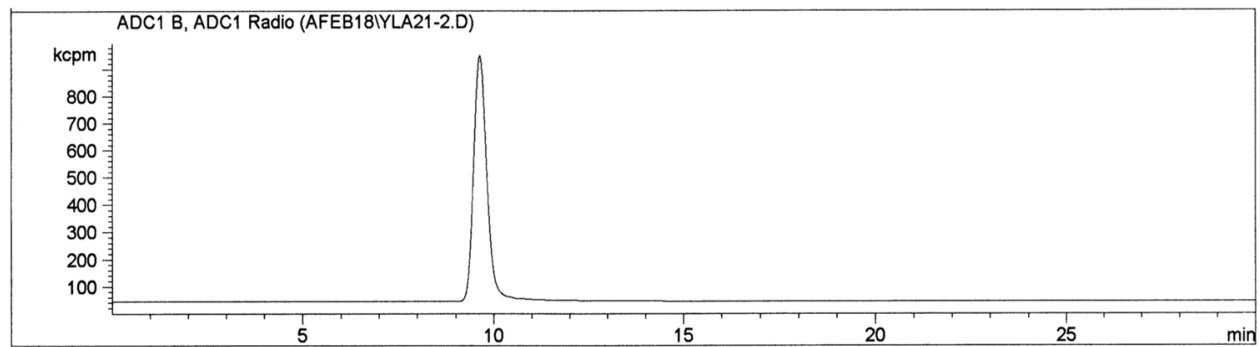

Figure 3. Representative anion exchange radio-HPLC chromatogram of the $\left[{ }^{211} \mathrm{At}\right] \mathrm{NaAt}$ isolated using the Te column method.

${ }^{211}$ At decayed. Calibration curves were generated using Bi and Te standard solutions at concentrations of 1, 10, 50 $100 \mathrm{ppb}$, with $\mathrm{R}^{2} \geq 0.9995$. Recoveries of the internal standards (ISTDs) were very close to $100 \%$ for all samples including calibration standards. On average, the concentration of residual $\mathrm{Bi}$ in the isolated ${ }^{211} \mathrm{At}$ solution was 3.0 ppm, which is slightly higher than that of the ${ }^{211}$ At isolated using the DIPE method (Table 4). The concentration of the Te contaminant in the isolated ${ }^{211}$ At solution is rather high, about $32.8 \mathrm{ppm}$ on average. However, it should be noted that ${ }^{211}$ At-labeled MAb prepared from Te column isolated ${ }^{211} \mathrm{At}$ and purified by a size-exclusion (PD-10) column had significantly reduced $\mathrm{Bi}$ and Te concentrations of about 0.05 and $0.04 \mathrm{ppm}$, respectively (Table 4).

Anion exchange radio-HPLC analyses were performed to evaluate the radiochemical purity of the isolated ${ }^{211}$ At. A representative radio-chromatogram is shown in Fig. 3. Only one radiopeak at 9.5 min has been observed for several ${ }^{211}$ At solutions purified using the Te column method $(n>10)$, which suggests radiochemical purity $>99 \%$ can be consistently achieved using the Te column method.

\section{Discussion}

Astatine-211 can be rapidly absorbed on metallic $\mathrm{Te}$ in $\mathrm{HCl}$ in the presence of $\mathrm{SnCl}_{2}$ and eluted by a solution of 1-2 $\mathrm{M} \mathrm{NaOH}$. The high affinity of $\mathrm{At}^{-}$to elemental $\mathrm{Te}$ in $\mathrm{HCl}$ might be the result of the formation of a coordination bond between the surface Te and the highly polarizable $\mathrm{At}^{-19}$. In the literature, Te columns were used for separation of ${ }^{211}$ At from irradiated thorium targets ${ }^{19}$ or polonium impurities, when ${ }^{211}$ At is produced via high energy proton induced spallation of thorium ${ }^{19}$ or the ${ }^{209} \mathrm{Bi}\left({ }^{7} \mathrm{Li}, 5 \mathrm{n}\right){ }^{211} \mathrm{Rn} \rightarrow{ }^{211}$ At route ${ }^{20}$, respectively. In those scenarios, the solutions containing ${ }^{211} \mathrm{At} /$ impurities do not contain large amounts of $\mathrm{HNO}_{3}$ and can be readily diluted and constituted to approximately $0.1 \mathrm{M} \mathrm{SnCl}_{2}$ in $6 \mathrm{M} \mathrm{HCl}$ prior to loading onto the Te column. However, dissolution of our Bi targets which contain 4-5 grams of Bi metal requires the use of $15-17 \mathrm{~mL}$ of $10 \mathrm{M}$ or concentrated $\mathrm{HNO}_{3}$. Hydroxylamine can reduce $\mathrm{HNO}_{3}$ to $\mathrm{HNO}_{2}$ which further reacts with $\mathrm{NH}_{3} \mathrm{OH}^{+}$and produce gaseous $\mathrm{N}_{2} \mathrm{O}(\mathrm{g})$, and $\mathrm{N}_{2}(\mathrm{~g})$, so it is used to convert the nitrate matrix to $\mathrm{HCl}^{21,22}$. The addition of $\mathrm{NH}_{2} \mathrm{OH} \cdot \mathrm{HCl}$ also eliminates the need for using $\mathrm{SnCl}_{2}$ in the solution transferred onto the Te column. It is likely that $\mathrm{NH}_{2} \mathrm{OH} \cdot \mathrm{HCl}$ reduces astatine in other oxidation states to astatide, the astatine species that might be required for the Te column method to work properly. 
Compared to the DIPE extraction method, using $\mathrm{NH}_{2} \mathrm{OH} \cdot \mathrm{HCl}$ for converting the $\mathrm{HNO}_{3}$ solution containing the dissolved $\mathrm{Bi}$ target to a $\mathrm{HCl}$ matrix is not only easier to automate, but can be faster than distilling the $\mathrm{HNO}_{3}$ to dryness. It takes $\sim 25 \mathrm{~min}$ to completely destroy the nitrate, adding the $\mathrm{NH}_{2} \mathrm{OH} \cdot \mathrm{HCl}$ solution $\left(\mathrm{V}_{\min }=52 \mathrm{~mL}\right)$ using the semi-automated system, which is comparable to the time it takes to remove the $\mathrm{HNO}_{3}$ by distillation $(\sim 30 \mathrm{~min})^{12}$. However, we found that not all of the nitrate needs to be destroyed to obtain good isolation yields. In fact, adding $52 \%$ of $\mathrm{V}_{\text {min }}$ provides high ${ }^{211} \mathrm{At}$ isolation yields as well as high B10-conjugated MAb labeling yields (Table 3).

The overall run times of the semi-automated ${ }^{211} \mathrm{At}$ isolation experiments are $20-30$ min shorter than those of the DIPE extraction process (Table 2). The high affinity of $\mathrm{At}^{-}$to elemental Te allows adsorption of ${ }^{211} \mathrm{At}$ onto Te columns and washing the Te columns with $\mathrm{HCl}$ and $\mathrm{H}_{2} \mathrm{O}$ at high flow rates of $6 \mathrm{~mL} / \mathrm{min}$. Also, the elution of ${ }^{211} \mathrm{At}$ from the Te column using $\mathrm{NaOH}$ is very efficient, averaging $93 \%$ of the ${ }^{211} \mathrm{At}$ in $2 \mathrm{~mL}$ volume at a flow rate of $60 \mathrm{~mL} / \mathrm{min}$. It should be noted the $\mathrm{NaOH}$ back extraction step in the DIPE extraction method can takes $10-20 \mathrm{~min}$ to finish ${ }^{12}$. The fast flow rates used in the Te column isolation process are critical for achieving good ${ }^{211}$ At isolation yields in a reasonable amount of time, especially, considering the volume of ${ }^{211}$ At solution passing over the Te columns is rather large.

Astatine-211 solutions obtained using the DIPE liquid-liquid extraction method can have multiple astatine species which can lead to low radiochemical purity ${ }^{12}$. In contrast, ${ }^{211}$ At solutions isolated using Te columns consistently provide only astatide in a radiochemical purity $>99 \%$. This might be due to ${ }^{211}$ At being reduced to astatide by $\mathrm{NH}_{2} \mathrm{OH} \cdot \mathrm{HCl}$ before being transferred onto the column. However, it must be noted that a small amount of tellurium metal is dissolved in $1 \mathrm{M} \mathrm{NaOH}$ as ${ }^{211}$ At is eluted off the column and $\mathrm{Na}_{2} \mathrm{TeO}_{3}$ is a weak reducing agent. While untested at this time, the presence of $\mathrm{Na}_{2} \mathrm{TeO}_{3}$ might cause problems for astatine labeling, especially electrophilic astatination reactions. Thus, methods for purifying ${ }^{211} \mathrm{At}$ from the $\mathrm{Te}$ (and possibly $\mathrm{Bi}$ ) impurities need to be evaluated for applications that require higher purity.

In conclusion, Te columns provide an alternative method for efficiently isolating ${ }^{211} \mathrm{At}$ from irradiated Bi targets. The isolated ${ }^{211}$ At solution is of high radiochemical purity and is suitable for B10-conjugated MAb labeling. A semi-automated process based on the Te column method has been demonstrated. Studies to evaluate the influence of the mesh size of the Te powder used on the ${ }^{211}$ At isolation yield are on-going. As future work, the geometry of the Te column, the volumes of reagents including $1.5 \mathrm{M} \mathrm{HCl}$, D.I. $\mathrm{H}_{2} \mathrm{O}$ and $1 \mathrm{M} \mathrm{NaOH}$ need to be optimized to minimize the overall run time and to reduce the volume of the final product to $0.5 \mathrm{~mL}$ or less.

\section{Methods}

Reagents and general procedures. The chemicals and reagents used were purchased from VWR International (Radnor, PA), Sigma Aldrich (St. Louis, MO) or Fisher Scientific (Pittsburgh, PA), and were used without further purification unless otherwise specified. Empty Mini Spe-ed column cartridges were obtained from Applied Separations (Allentown, PA). ICP-MS tuning solution and $10 \mu \mathrm{g} / \mathrm{mL}$ standard solutions of Bi and Te were obtained from Inorganic Ventures (Christiansburg, VA). Monoclonal antibodies were obtained from the Fred Hutchinson Cancer Research Center Biologics Production Facility and isothiocyanato-phenethyl-closo-decaborate (2-) (B10-NCS)-conjugated MAbs were prepared in house as previously described ${ }^{23}$. Astatine- 211 was produced by irradiation of $\mathrm{Bi}$ metal on an aluminum target support with $29 \mathrm{MeV} \alpha$-particles using the Scanditronix MC50 cyclotron as previously described ${ }^{24}$. Various solutions containing ${ }^{211}$ At generated before and after Te column separation were measured in a Capintec CRC-55tR dose calibrator using the calibration setting number 44. Astatination of the B10-conjugated MAbs with ${ }^{211}$ At isolated using Te columns were conducted as previously described ${ }^{25}$.

Determine the minimal volume of $\mathrm{NH}_{2} \mathrm{OH} \cdot \mathrm{HCl}$. Determining the production rate of each of the products generated by the $\mathrm{HNO}_{3}$ and $\mathrm{NH}_{2} \mathrm{OH} \cdot \mathrm{HCl}$ redox reaction was not attempted. It seemed that accurately assigning a defined stoichiometry to this reaction was not possible, thus the minimal volume of $35 \% \mathrm{NH}_{2} \mathrm{OH} \cdot \mathrm{HCl}$ required to destroy all the nitrate ions in the dissolved Bi target solution $\left(\mathrm{V}_{\min }\right)$ was determined experimentally.

To mimic the semi-automated isolation process, $4.25 \mathrm{~g}$ of $\mathrm{Bi}$ metal was dissolved in $15 \mathrm{~mL}$ of $10 \mathrm{M} \mathrm{HNO}_{3}$. The resultant solution was split into three $5-\mathrm{mL}$ fractions and $35 \%$ aqueous $\mathrm{NH}_{2} \mathrm{OH} \cdot \mathrm{HCl}$ was added dropwise at a flow rate of approximately $2 \mathrm{~mL} / \mathrm{min}$ using a $25-\mathrm{mL}$ burette. The completion of the $\mathrm{NH}_{2} \mathrm{OH} \cdot \mathrm{HCl}$ and nitric acid reaction was observed as a cessation of bubbling. Nitrate/nitrite test paper (EMD Millipore ${ }^{\mathrm{TM}}$ ) was used to verify the nitrate ion was below the detection limit (10 ppm).

Manual ${ }^{211}$ At isolation using Te columns. Each Mini Spe-ed column cartridge (Applied Separations, Allentown, PA) was filled with $1 \mathrm{~g}$ (dry weight) of tellurium metal powder ( -200 mesh). The columns were washed sequentially by $20 \mathrm{~mL}$ of $2 \mathrm{M} \mathrm{NaOH}, 3 \mathrm{M} \mathrm{HCl}$ and D.I. $\mathrm{H}_{2} \mathrm{O}$. Prior to use, the Te columns were pre-equilibrated with $20 \mathrm{~mL}$ of $0.1 \mathrm{M} \mathrm{SnCl}_{2}$ in $6 \mathrm{M} \mathrm{HCl}$ or $1.5 \mathrm{M} \mathrm{HCl}$.

An irradiated $\mathrm{Bi}$ target containing $\sim 0.96 \mathrm{GBq}(\sim 26 \mathrm{mCi})$ of ${ }^{211}$ At was placed Bi face down in a plastic container. A total of $17 \mathrm{~mL}$ of concentrated $\mathrm{HNO}_{3}$ was manually added to dissolve the $\mathrm{Bi}$ and ${ }^{211}$ At. Because $10 \mathrm{M}$ $\mathrm{HNO}_{3}$ rather than concentrated $\mathrm{HNO}_{3}$ would be used for target dissolution in the semi-automated ${ }^{211}$ At isolation process, $1 \mathrm{~g}$ of high purity (99.999\% trace metal basis) Bi beads were dissolved in $3 \mathrm{~mL}$ of $10 \mathrm{M}$ nitric acid to mimic the $\mathrm{Bi}^{3+}$ and $\mathrm{NO}_{3}{ }^{-}$concentration in the dissolved $\mathrm{Bi}$ target solution obtained using the semi-automated process. The resultant solution was spiked with $0.5-1 \mathrm{~mL}$ concentrated $\mathrm{HNO}_{3}$ of dissolved irradiated Bi targets. Depending on the chromatographic conditions to be evaluated, the obtained solution was adjusted accordingly.

Loading in $0.1 \mathrm{M} \mathrm{SnCl}_{2}$ in $6 \mathrm{M} \mathrm{HCl}$. Thirty five percent $\mathrm{NH}_{2} \mathrm{OH} \cdot \mathrm{HCl}$ was added dropwise until the cessation of bubbling. The solution was then adjusted to $0.1 \mathrm{M} \mathrm{SnCl}_{2}$ in $6 \mathrm{M} \mathrm{HCl}$ using $1 \mathrm{M} \mathrm{SnCl}_{2}$ and concentrated $\mathrm{HCl}$. After loading the resultant solution onto the Te column, the column was eluted with $20 \mathrm{~mL}$ of $0.1 \mathrm{M} \mathrm{SnCl}_{2}$ in $6 \mathrm{M} \mathrm{HCl}$, followed by $20 \mathrm{~mL}$ of $6 \mathrm{M} \mathrm{HCl}$, D.I. $\mathrm{H}_{2} \mathrm{O}$ and $2 \mathrm{~mL}$ of $1-2 \mathrm{M} \mathrm{NaOH}$. 
Loading in $1.5 \mathrm{M} \mathrm{HCl}$. Various amounts of $35 \%$ aqueous $\mathrm{NH}_{2} \mathrm{OH} \cdot \mathrm{HCl}$ were added dropwise, followed by $3-4.35 \mathrm{~mL}$ of $8 \mathrm{M} \mathrm{HCl}$ to reconstitute the solution to approximately $1.5 \mathrm{M} \mathrm{HCl}$. After loading the resultant solution onto the Te column, the column was eluted by $20 \mathrm{~mL}$ of $1.5 \mathrm{M} \mathrm{HCl}$, D.I. $\mathrm{H}_{2} \mathrm{O}$ and then $2 \mathrm{~mL}$ of $1-2 \mathrm{M} \mathrm{NaOH}$.

The semi-automated ${ }^{211}$ At isolation process. The schematic of the semi-automated system is shown in Fig. 2 and component details of the system are provided in Fig. S1. An irradiated Bi target containing $\sim 0.96$ $\mathrm{GBq}(\sim 26 \mathrm{mCi})$ of ${ }^{211}$ At was manually put into the polyetherimide $\left(\mathrm{ULTEM}^{\mathrm{TM}}\right)$ dissolution chamber ${ }^{18}$, then the semi-automated ${ }^{211} \mathrm{At}$ isolation process was started from the computer. The magnetic stirrer was turned on manually. Using the $10-\mathrm{mL}$ syringe installed on the Hamilton syringe pump $\mathbf{A}, 15 \mathrm{~mL}$ of $10 \mathrm{M} \mathrm{HNO}_{3}$ (1) was pumped through the dissolution chamber to dissolve the target at a flow rate of $2.4 \mathrm{~mL} / \mathrm{min}$. The $\mathrm{HNO}_{3}$ solution obtained from the dissolved target was collected in the $250-\mathrm{mL}$ round bottom flask. Air (2) was pushed through the dissolution chamber to ensure all the $\mathrm{HNO}_{3}$ was transferred into the round bottom flask. D. I. $\mathrm{H}_{2} \mathrm{O}(3)$ was used to rinse the $10-\mathrm{mL}$ syringe and was moved into Waste 1 . Using the same $10-\mathrm{mL}$ syringe, at a flow rate of $2.4 \mathrm{~mL} /$ min, $65 \mathrm{~mL}$ or $80 \mathrm{~mL}$ of $35 \% \mathrm{NH}_{2} \mathrm{OH} \cdot \mathrm{HCl}(4)$ was added to the dissolved target solution to destroy the nitrate ions, followed by $17.1 \mathrm{~mL}$ or $22 \mathrm{~mL}$ of $8 \mathrm{M} \mathrm{HCl} \mathrm{(5)} \mathrm{to} \mathrm{make} \mathrm{the} \mathrm{solution} 1.5 \mathrm{M}$ in $\mathrm{HCl}$. The total volume after these steps was about $97 \mathrm{~mL}$ or $117 \mathrm{~mL}$, depending on volume of $35 \% \mathrm{NH}_{2} \mathrm{OH} \cdot \mathrm{HCl}$ used. Using a $25-\mathrm{mL}$ syringe on Hamilton syringe pump B, $25 \mathrm{~mL}$ of $1.5 \mathrm{M} \mathrm{HCl}(\mathbf{6})$ was passed over the Te column into Waste 1 to pre-equilibrate the column. After the column was equilibrated, $21.5 \mathrm{~mL}$ of the dissolved target solution was transferred into a $25-\mathrm{mL}$ loop, then flowed through the Te column at a flow rate of $6 \mathrm{~mL} / \mathrm{min}$. This step was repeated multiple times to load all the radioactive solution onto the column. During this process, the effluent from the column containing $\mathrm{Bi}$ and other impurities was delivered into Waste 2 . The Te column was then rinsed with 20 or $40 \mathrm{~mL}$ of $1.5 \mathrm{M} \mathrm{HCl}$, followed by 20 or $40 \mathrm{~mL}$ of D.I. $\mathrm{H}_{2} \mathrm{O}$. Finally, the column was eluted using $5-7 \mathrm{~mL}$ of $2 \mathrm{M} \mathrm{NaOH}$ in $1 \mathrm{~mL}$ fractions at a flow rate of $60 \mathrm{~mL} / \mathrm{min}$.

Radio-HPLC and ICP-MS analysis. Radio-HPLC. Radio-HPLC analyses were performed on the ${ }^{211}$ At solutions using a Hewlett-Packard model 1050 HPLC (Hewlett-Packard Company, Palo Alto, CA) with a Beckman Model 170 Radioisotope Detector (Beckman-Coulter, Brea, CA). Isocratic analyses were conducted on a Dionex IonPac AS-20 anion exchange column with a Dionex AG-20 guard column (Dionex, Sunnyvale, CA), eluting with a $50 \mathrm{mM} \mathrm{NaOH}$ solution at $1.3 \mathrm{~mL} / \mathrm{min}$.

ICP-MS. Determination of the concentrations of $\mathrm{Bi}$ and Te impurities in the isolated ${ }^{211} \mathrm{At}$ product was carried out using an Agilent 7900 ICP-MS and the associated Mass Hunter Workstation software package. High purity $\mathrm{HNO}_{3}$ and ultrapure $\mathrm{H}_{2} \mathrm{O}(\geq 17.8 \mathrm{M} \Omega \cdot \mathrm{cm})$ were used to prepare ICP-MS samples. Ten $\mu \mathrm{L}$ aliquots of ${ }^{211}$ At solutions were diluted 1,000 times in $5 \% \mathrm{HNO}_{3}$. Samples containing antibodies were heated for $1 \mathrm{~h}$ in concentrated high purity $\mathrm{HNO}_{3}$ at $99^{\circ} \mathrm{C}$ before diluting to $5 \% \mathrm{HNO}_{3}$. A 100 -ppb solution of $\mathrm{Co}, \mathrm{Y}, \mathrm{Ce}$, and $\mathrm{Tl}$ was used as internal standard (ISTD). The ISTD was aspirated by a separate line and mixed with samples or standard solutions before the nebulizer using an online ISTD addition connector.

\section{Data availability}

All data generated and analyzed during this study are included in this article and are also available from the authors upon request.

Received: 24 July 2019; Accepted: 28 October 2019;

Published online: 18 November 2019

\section{References}

1. Chen, Y. et al. Durable donor engraftment after radioimmunotherapy using $\alpha$-emitter astatine-211-labeled anti-CD45 antibody for conditioning in allogeneic hematopoietic cell transplantation. Blood 119, 1130-1138 (2012).

2. Green, D. J. et al. Astatine-211 conjugated to an anti-CD20 monoclonal antibody eradicates disseminated B-cell lymphoma in a mouse model. Blood 125, 2111-2119 (2015).

3. Zalutsky, M. R., Reardon, D. A., Pozzi, O. R., Vaidyanathan, G. \& Bigner, D. D. Targeted $\alpha$-particle radiotherapy with ${ }^{211}$ At-labeled monoclonal antibodies. Nuclear Medicine and Biology 34, 779-785 (2007).

4. Baidoo, K. E., Yong, K. \& Brechbiel, M. W. Molecular Pathways: Targeted $\alpha$-Particle Radiation Therapy. Clin Cancer Res 19, 530-537 (2013).

5. Aneheim, E., Jensen, H., Albertsson, P. \& Lindegren, S. Astatine-211 labeling: a study towards automatic production of astatinated antibodies. J Radioanal Nucl Chem 303, 979-983 (2015).

6. Hadley, S. W., Wilbur, D. S., Gray, M. A. \& Atcher, R. W. Astatine-211 labeling of an antimelanoma antibody and its Fab fragment using $\mathrm{N}$-succinimidyl p- $\left[{ }^{211} \mathrm{At}\right]$ astatobenzoate: comparisons in vivo with the p- $\left.{ }^{[25} \mathrm{I}\right]$ iodobenzoyl conjugate. Bioconjugate Chemistry 2, 171-179 (1991).

7. Koziorowski, J., Lebeda, O. \& Weinreich, R. A cryotrap as flow reactor for synthesis of ${ }^{211}$ At labelled compounds. Applied Radiation and Isotopes 50, 527-529 (1999).

8. Lindegren, S., Bäck, T. \& Jensen, H. J. Dry-distillation of astatine-211 from irradiated bismuth targets: a time-saving procedure with high recovery yields. Applied Radiation and Isotopes 55, 157-160 (2001).

9. Wilbur, D. S. et al. Preparation and evaluation of para- $\left[{ }^{211} \mathrm{At}\right]$ astatobenzoyl labeled anti-renal cell carcinoma antibody A6H F(ab') ${ }_{2}$. In vivo distribution comparison with para- $\left.{ }^{[125} \mathrm{I}\right]$ iodobenzoyl labeled $\mathrm{A} 6 \mathrm{H} \mathrm{F}\left(\mathrm{ab}^{\prime}\right)_{2}$. Nuclear Medicine and Biology 20, $917-927$ (1993).

10. Schwarz, U. P. et al. Preparation of ${ }^{211}$ At-Labeled Humanized Anti-Tac Using ${ }^{211}$ At Produced in Disposable Internal and External Bismuth Targets. Nuclear Medicine and Biology 25, 89-93 (1998).

11. Doberenz, V. et al. Preparation of astatine of high specific activity in solutions of a given composition. Radiochem. Radioanal. Lett. 52, 119-27 (1982).

12. Balkin, E. R. et al. Evaluation of a Wet Chemistry Method for Isolation of Cyclotron Produced $\left[{ }^{211} \mathrm{At}\right]$ Astatine. Applied Sciences 3 , 636-655 (2013)

13. Yordanov, A. T. et al. Wet harvesting of no-carrier-added ${ }^{211} \mathrm{At}$ from an irradiated ${ }^{209} \mathrm{Bi}$ target for radiopharmaceutical applications. Journal of Radioanalytical and Nuclear Chemistry 262, 593 (2004). 
14. Zona, C. et al. Wet-chemistry method for the separation of no-carrier-added ${ }^{211} \mathrm{At} /{ }^{211 \mathrm{~g}} \mathrm{Po}$ from ${ }^{209} \mathrm{Bi}$ target irradiated by alpha-beam in cyclotron. J Radioanal Nucl Chem 276, 819-824 (2008).

15. Neirinckx, R. D. \& Smit, J. A. Separation of astatine-211 from bismuth metal. Analytica Chimica Acta 63, 201-204 (1973).

16. Ekberg, C., Jensen, H., Mezyk, S. P., Mincher, B. J. \& Skarnemark, G. Extraction of ${ }^{211}$ At from nitric acid solutions into various organic solvents for use as an $\alpha$-source for radiation chemistry studies. J Radioanal Nucl Chem 314, 235-239 (2017).

17. Neumann, H. M. Solvent distribution studies of the chemistry of astatine. Journal of Inorganic and Nuclear Chemistry 4, 349-353 (1957).

18. O'Hara, M. J. et al. An automated flow system incorporating in-line acid dissolution of bismuth metal from a cyclotron irradiated target assembly for use in the isolation of astatine-211. Applied Radiation and Isotopes 122, 202-210 (2017).

19. Bochvarova, M., Do, K. T., Dudova, I., Norseev, Y. V. \& Khalkin, V. A. Use of columns filled with crystalline tellurium for producing radiochemically pure astatine preparation. Radiokhimiya 14, 858-65 (1972).

20. Crawford, J. R. et al. Development of a preclinical ${ }^{211} \mathrm{Rn} /{ }^{211}$ At generator system for targeted alpha therapy research with ${ }^{211}$ At. Nuclear Medicine and Biology 48, 31-35 (2017).

21. Bennett, M. R., Maya, L., Brown, G. M. \& Posey, F. A. Oxidation of hydroxylamine by nitrous and nitric acids. Inorg. Chem. 21, 2461-2468 (1982).

22. Pembridge, J. R. \& Stedman, G. Kinetics, mechanism, and stoicheiometry of the oxidation of hydroxylamine by nitric acid. J. Chem. Soc., Dalton Trans. 1657-1663, https://doi.org/10.1039/DT9790001657 (1979).

23. Wilbur, D. S. et al. Reagents for Astatination of Biomolecules. 2. Conjugation of Anionic Boron Cage Pendant Groups to a Protein Provides a Method for Direct Labeling that is Stable to in Vivo Deastatination. Bioconjugate Chem. 18, 1226-1240 (2007).

24. Gagnon, K. et al. Design and evaluation of an external high-current target for production of ${ }^{211}$ At. Journal of Labelled Compounds and Radiopharmaceuticals 55, 436-440 (2012).

25. Li, Y. et al. cGMP production of astatine-211-labeled anti-CD45 antibodies for use in allogeneic hematopoietic cell transplantation for treatment of advanced hematopoietic malignancies. PLOS ONE 13, e0205135 (2018).

\section{Acknowledgements}

The authors gratefully acknowledge the staff of the U.W. Medical Cyclotron Facility, especially E.F. Dorman and R.C. Emery, for assistance in obtaining irradiated bismuth targets. This research is supported by the U.S. Department of Energy Isotope Program, managed by the Office of Science for Nuclear Physics. The funding came under research grants DE- SC0013618 and DE-SC0018013.

\section{Author contributions}

D.S.W. conceived the project and obtained funding. Y.L., M.-K.C., D.K.H., T.M.M., R.W. and M.G.F. conducted the experiments. All authors discussed the results and contributed to the method development. Y.L. and D.S.W. prepared the original draft and M-K.C., D.K.H., T.M.M., R.W. and M.G.F. reviewed and edited the manuscript.

\section{Competing interests}

The authors declare no competing interests.

\section{Additional information}

Supplementary information is available for this paper at https://doi.org/10.1038/s41598-019-53385-X.

Correspondence and requests for materials should be addressed to Y.L.

Reprints and permissions information is available at www.nature.com/reprints.

Publisher's note Springer Nature remains neutral with regard to jurisdictional claims in published maps and institutional affiliations.

(c) (i) Open Access This article is licensed under a Creative Commons Attribution 4.0 International

License, which permits use, sharing, adaptation, distribution and reproduction in any medium or format, as long as you give appropriate credit to the original author(s) and the source, provide a link to the Creative Commons license, and indicate if changes were made. The images or other third party material in this article are included in the article's Creative Commons license, unless indicated otherwise in a credit line to the material. If material is not included in the article's Creative Commons license and your intended use is not permitted by statutory regulation or exceeds the permitted use, you will need to obtain permission directly from the copyright holder. To view a copy of this license, visit http://creativecommons.org/licenses/by/4.0/.

(c) The Author(s) 2019 